\title{
AN ASSESSMENT - WATER QUALITY MONITORING PRACTICES AND SEWER ROBOTIC SYSTEMS
}

\author{
Saniya Ansari ${ }^{1}$, S. M. Khairnar ${ }^{2}$, Ravindra R. Patil ${ }^{3}$, Rupali S. Kokate ${ }^{4}$ \\ ${ }^{1}$ Associate Professor, Department of E \& TC Engineering, DYPSOE, Pune, India \\ ${ }^{2}$ Professor, Engineering Science Department, DYPSOE, Pune, India \\ ${ }^{3,4}$ Junior research Fellow, SPRING Project, DYPSOE, Pune, India \\ Email: 1ansari.saniya6@gmail.com, 2smkhairnar2007@gmail.com,393gravi@gmail.com, ${ }^{3}$ anushkamahale@gmail.com
}

\begin{abstract}
Water pollution has become a global issue and creating a severe problems due to contamination of various water sources such as agricultural waste, industrial waste, and sewage waste etc. So, the available sensory systems, nodes, and techniques plays a crucial role in identification of harmful pollutants in distinct water resources. The water pollutants monitoring techniques with prospered tools and sensors have been unfolded to find gap for future research maneuver. The need of real-time newer sensory system has been put forwarded for identification of mostly occurring harmful pollutants such as BOD, COD, TSS, and Hydrogen sulfide in examination of water quality.

In this modern advancement, robotic systems have taken an intrinsic stand in diverse fields of humankind. An underground infrastructure is a base of modern society. In this paper, the existing methodologies and developed sewer robotic systems have been discussed and concluded on their applications, limitations and impact on realistic scenarios. Also, the cardinal point is revealed that previous art work focused only on sewer defect identification but not standardized work on sewer blockages detection and removal. So, the sewer robotic system with features of cost effectiveness and standardized accuracy matrix should be developed to resolve sewer blockage issues and followed by human scavenging. The survey outcomes extend a province of sewer robotics to resolve blockages issues of buried sewers of distinct diameters in real-time with substantial methodology.
\end{abstract}

Keywords: Water quality sensors, Water Monitoring techniques, Sewer Robots, Sewer Examination Methodologies, Assessment, Discernments

\section{Introduction}

Polluted water needs to be clean and pure by removing the hazardous pollutants to protect human health from various types of diseases. The clean water is contaminated due to impurities added by industrial and agricultural discharge. The amount of largest discharged of sewages into the lakes and rivers affects not only on environment but also on human beings leading to various health issues and diseases. Chemical Pollution occurs when chemicals resulting into the environment by human activity. The water, soil, acid rain, greenhouse gases and ozone gas contaminating air are some examples of it. Chemical contaminants present in water are color less so it cannot be detected by observing human eye. The main chemicals available in water are $\mathrm{pH}$, dissolved oxygen-O2, temperature, electrical conductivity, Oxidation reduction potential, turbidity, and dissolved ions etc. in [1].

The universally, every nation spend a large amount on assessment of buried infrastructure. The complex issues have to face during these assessment campaigns. So, the sewer robotics has become a comprehensive research area from earlier. The no autonomy, semi-autonomy, and full autonomy are the crucial types of robotic systems. The PIRAT, KARO, KURT, MAKRO, and KANTARO are traditional sewer robotic inspection systems as well as modern SIAR Project, which all clarify about attempts. All these systems focused only on defect identification but not tried to resolve any issue in real-time. Most commonly used sewer assessment techniques such as the SSET, CCTV, and Laser Scanning. The computer vision methodologies also have been put forwarded to be cognizant of recent approaches in sewer inspection techniques.

The paper is presented into six section. The preceding exploration on water quality monitoring has been specified in section II and sensor-based pollutant detection approaches in section III. The section IV investigates about earlier implemented sewer robotic systems whereas inspection methodologies and PMC survey report have been stated clearly in section V. All in all, the assessment of has been concluded in section VI.

\section{Previous Art work on Water Quality Monitoring}

Naturally, few water pollutants occur mostly such as heavy metals, nitrogen oxide etc. and few are formed during their chemical reaction with naturally occurring components in agriculture or pharmaceuticals industries. The given research clarifies about it.

R. Karthik Kumar et al. have developed a solar monitoring system by using wireless sensor networks to provide power supply to sensor network by using MATLAB [2]. Pradeepkumar $M$ et al. introduced the architecture of 
cloud computing into IoT as well as sensors network to make that sensor data accessible worldwide in [3]. Kedia Nikhil et al. designed a sensor cloud-based network for water monitoring in rural area. This system can directly contact to government in case of quality issue of water as system has facility of mobile network operator in [4].

Ahmed et al. presented the survey of various water pollutants like heavy metals, pesticides, agriculture waste and petrochemical hydrocarbon. The syntheses of pesticides, plastics, petrochemicals are the main source of pollutants created in the environment in [5].

Congas Koran et al. have elaborated main parameters like dissolved oxygen, temperature, $\mathrm{pH}$, electrical conductivity. For water quality monitoring, concentration of dissolved oxygen must be low, temperature and $\mathrm{pH}$ must be undesirable. Pollutants carried out by storm water contains bacteria, nutrients, litter, oils, heavy metals and sediments in [6].

Peter Kruse has studied about the pollutants present in water by using Chemical Sensors, electrical sensors, electrochemical sensors and tested the various parameters like $\mathrm{pH}$, turbidity, temperature of water, humidity of surrounding environments etc. They suggested use of Data processing algorithm for establishment of sensor network to provide better platform for water pollution monitoring in [7]. Devisal Abdul Kailey al. have tested water sample in laboratories and designed a sensor network with the help of Thermistor, Glass electrode, flow Sensor, water level sensor, paleography to detect the parameters like temperature, dissolved oxygen, $\mathrm{pH}$, conductivity, flow rate, water level etc. They suggested that new advanced methods must be implemented to detect some advanced pollutants like BOD, COD, and TSS in [8].

Congas Koran et al. has designed an unmanned Ariel vehicle (UAV) system having Sensor nodes, water sampling cartridge and microcontroller. It measured parameters such as Dissolved Oxygen, temperature, $\mathrm{pH}$ etc. The presented system, first land on water surface and collect only three water samples of $130 \mathrm{ml}$ with $2.1 \mathrm{~kg}$ payload in [9]. Annasamy Gowri et al. presented the detail information about water pollution, categories of water pollutants like bacteria, disease causing agents, viruses, parasitic worms which eventually enters into sewage systems in [10].

\section{Existing Sensor Based Pollutant Detection Approaches}

Below mentioned approaches are currently used for the water pollutant detection and monitoring related parameters.

\section{A. Wireless Sensor Networks (WSN)}

In traditional methods, all samples are collected manually and send it to laboratories for finding the contaminants available in polluted water. These traditional method of finding contaminants in water requires special instruments and equipment's and skilled manpower to do the analysis. Traditional methods are very costly and more time consuming as well as real time monitoring is not possible. To overcome these drawbacks of traditional methods, situ methods has been designed for real time monitoring for water pollution using WSN in [11].

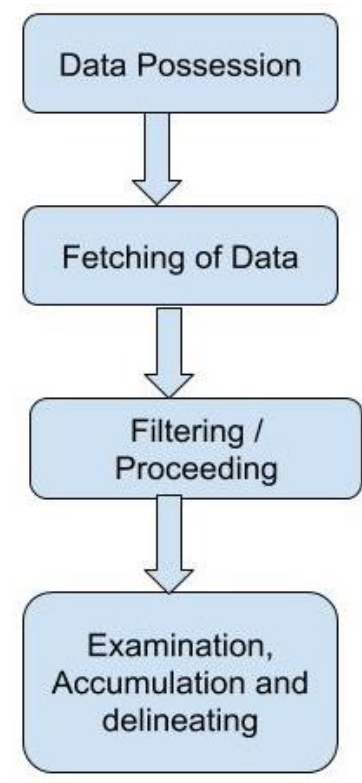

Fig. 1. Fig.1.WSN for Water Pollutant detection

The given figure 1 presents the WSN pipeline with the core building blocks which performs data acquisition, filtering/processing, data transfer, and final analysis of storage and reporting. In data acquisition, the spatially distributed wireless sensor nodes acquire samples from the water source at periodic intervals. Filtering requires specialized computation and benefits from devices that are able to perform computationally intensive operations locally for detection of water quality parameters, filtering techniques and efficient algorithms. The data is transferred from the source to the final destination using ZigBee, Wi-Fi, LTE, GSM or WiMAX etc. Finally, the data analysis, storage, and reporting will be done.

\section{B. Smart Sensors}

Smart sensors come under intelligent devices; it can easily capture data from environment with the help of built-in programmable microprocessors. Basically, Smart sensors are sensing element which are used for amplification of signals, filtering process for the combination of compensation and software data processing in [12]. All monitored data is processed analytically and later transmitted wirelessly to the destination nodes to provide various water quality parameters to the end user.

\section{Chemical Sensors}


Chemical sensors are small scale device that can able to detect and measure real time information of specific pollutants present in waters samples through the integration of a transducer with a micro zone where a chemical reaction takes place [13]. According to IUPAC, A chemical sensor is a device that transforms chemical information, ranging from the concentration of a specific sample component to total composition analysis and in to analytically useful signal.

\section{Biosensors}

A biosensor is an independent device, which provides specific quantitative or semi-quantitative analytical information using a biochemical receptor [14].

Earlier Implemented Sewer Robotic Systems

The implemented robotic platforms have been elucidated with acquired techniques concerning sewer issues.

Kirkham et al., came up with PIRAT (Pipe Inspection Real-Time Assessment Technique) which was semiautonomous robot for sewer inspection having tethered mechanism in [15]. In this, interpretation system had been used to operate an automatic evaluation of its sensory data. The damages had been detected and classified on the basis of three-dimensional model data by using the interpretation system with comprised AI techniques. The tasks such as finding out real damages and marking images for region of damages were performed by a human operator manually. It is antiquated system having poor performance attributes and techniques.

Kuntz et al., proposed KARO (KAnalRoboter) which was tethered, semi-autonomous sewer inspection system in [16]. The microwave sensor and a 3D optical sensor had been exerted for detecting purpose such as obstacles, larger pipe cracks, and pipe deformations. In PIRAT and KARO, both had no on-board control unit and were present at remote location.

Kirchner and Hertzberg initiated KURT (KanalUndersuchungs-Roboter-Testplatform) which had six-wheels with feature of autonomous navigation in [17]. It was an untethered robotic system. This system KURT1 had the ability to classify a pipe junction type. The odometry, infrared or ultrasound distance transducers, in-clinometers were the sensory aspects of KURT2 for obstacle detection and permissive lanks. The large size of ultrasound sensors and environmental aspects affected sensor performance in real time scenario.

Rome et al., developed MAKRO (Mehrsegmentiger Autonomer KanalROboter) full autonomous robot with untethered mechanism in [18]. The pipe blockages had been identified based on ultrasound range sensor and it had onboard resources. The distinct tasks used to perform by sensors such as obstacle and collision avoidance, motion control, landmark detection, and obstacles detection. The reliability was depending only on sensors and poor imaging algorithms. Nassiraei et al., inaugurated KANTARO which was a fully autonomous robot with un-tethered mechanism. It had intelligent modular architecture contained in working and sensor in [19]. The navigational landmarks had been detected by developed teeny and smart 2D laser scanner. Also pipe status and defects were evaluated by the fish eye camera. In this, the faults detection software was inferior.

Alejo et al., proposed SIAR (Sewer Inspection Autonomous Robot) system in which critical structural defects of sewer pipelines can be detected by utilizing 3D structure reconstruction in real-time in [20]. The RGB-D sensors and a robust wireless communication are the major facets of this invented system. I Vaani et al., introduced BhrtyArtana robot which had the ability to asses pipe state such as corrosion and cracks and for blockages, it had cutting assembly known as turbine for removing in [21]. The proximity sensor for detecting blockages and camera connected for getting realtime video feed.

Haurum and Moeslund inspected all the research done in the sewer assessment area for the last 25 years. The Closed-Circuit Television (CCTV) and Sewer Scanner and Evaluation Technology (SSET) have clarified for sewer assessment in [22]. They analyzed protocols, datasets, and algorithmic pipeline. They concluded that, the standardized evaluation metrics, datasets and open-source code should be available freely and publicly. Tur and Garthwaite surveyed the existing robotic tools and investigated issues for a triumphant sewer robot in [23]. An energy sources, data management, and communication issues had been deliberated. They focused on CCTV, SSET, robotic system with classification and working strategy, and sensing technology.

Mendonca et al. presented a new cost-effective robot with mechanical arm for Drilling, Cutting and Cleaning application in [24]. This arm was controlled by using android app through Arduino ATMEGA-328 micro-controller. The navigation had been achieved through moving assembly inside a range of 15 meters. The developed robotic system was very basic prototype but consisted a multifunctionality and novel mechanism. Saenz et al. proposed SVM-RS system for cleaning and inspecting large concrete pipes in [25]. The kinematics, cleaning method, sensor technique, communications, media supply, and control system and operator interface have been explicated for exerted system. The high-pressure water nozzles were the newer approach for cleaning intension.

Roussialian et al., invented a pipe inspection semiautonomous robot which had the peculiar design to move in tight areas within a pipe with different sizes such as of diameters ranging from 25 to $50 \mathrm{~cm}$. The developed system was compact in size as compared to available robots and it also crawled inside horizontal and vertical pipelines in [26]. It could measure the traveled distance as well as could provide inspected data to user at remote location. 
Design, Limitations and Moving mechanism of sewer robots have been specified.

In figure 2, exerted sewer robotic systems have been depicted to reveal their designs.
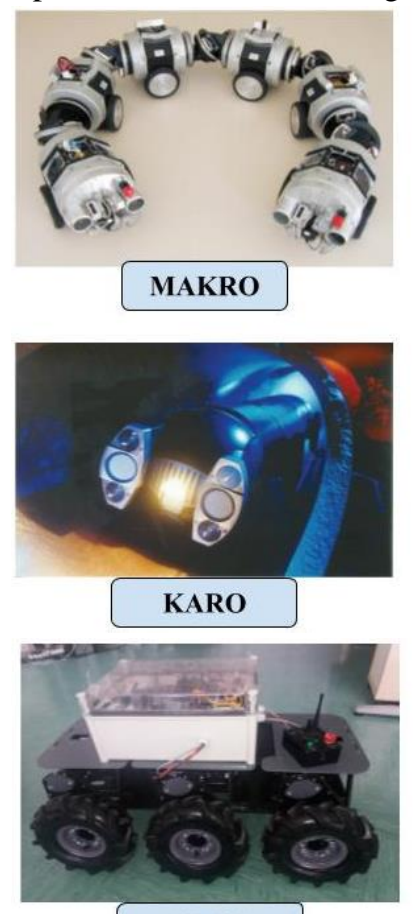

SIAR

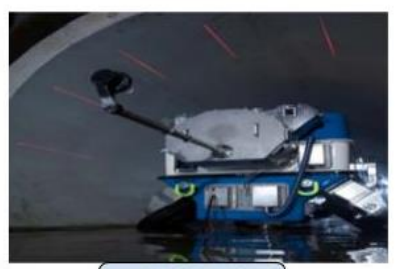

SVM-RS
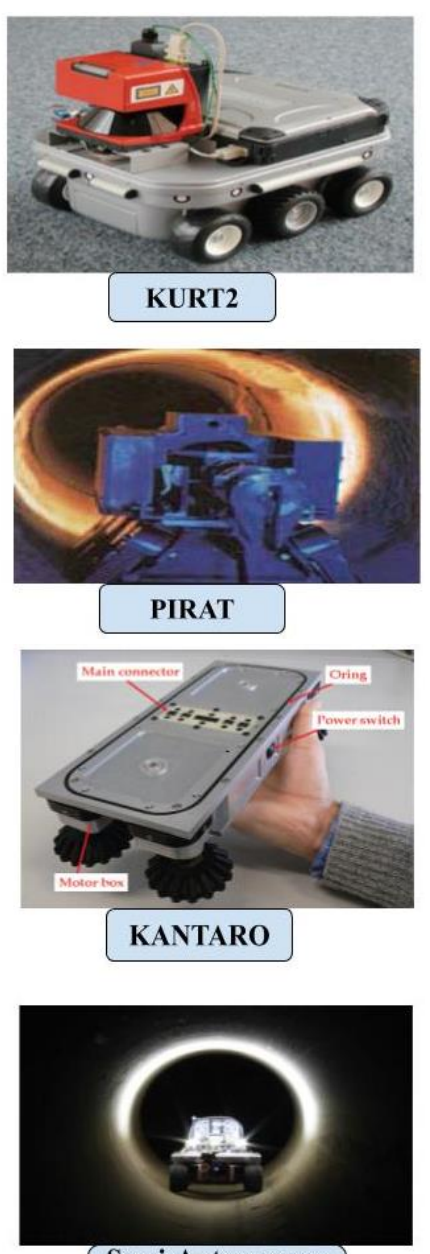

Semi-Autonomous Robot

\begin{tabular}{lll} 
PIRAT & Semi- & Credibility relates to an \\
& Autonomy & individual manipulator \\
KURT2 & Full & functioning influenced by \\
& Autonomy & surrounding parameters \\
\hline \hline
\end{tabular}

These robotic systems are systemized based on navigating methodology. In the below-given figure 3, types of robotic systems have been outlined.
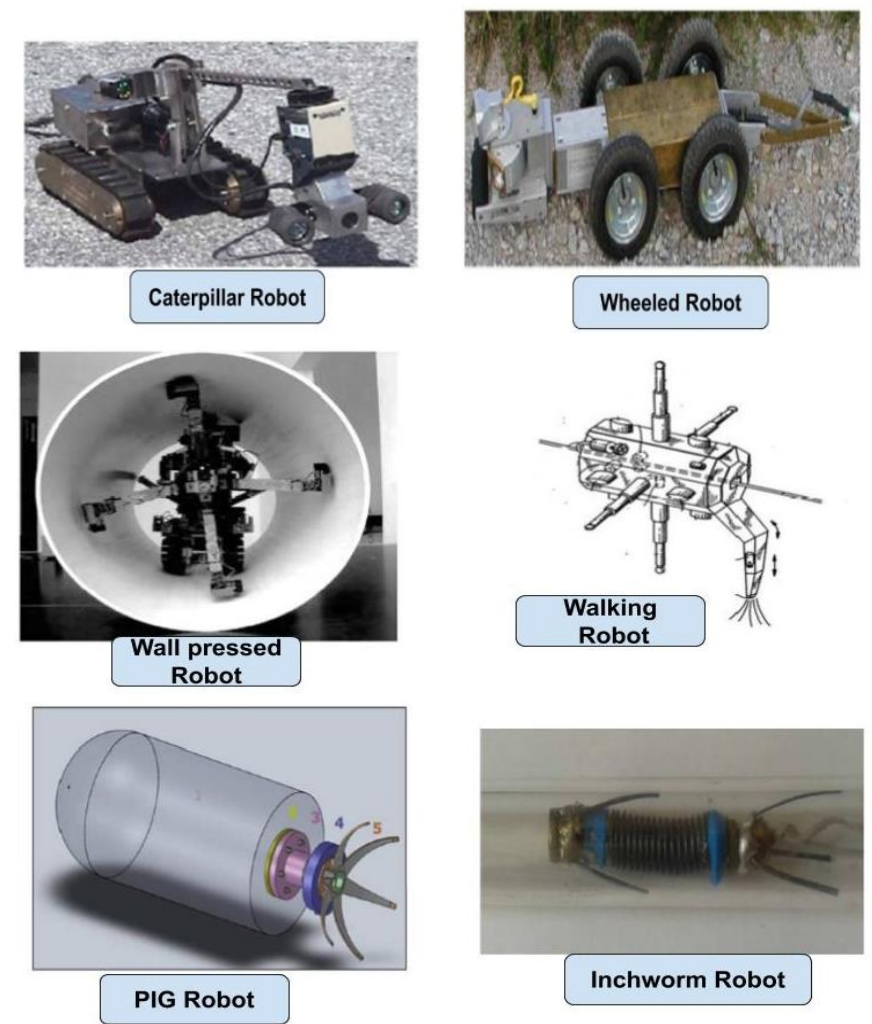

Fig. 3. Types of robotic systems based on navigating methodology

The key features of these navigating methodologies are given below.

- The wall pressed types of robots are generally ideal for vertical pipes and navigate without slipping.

- The PIG types of robots are also functional in sufficient quantity of flow.

- The wheeled type of robots applicable only for horizontal pipes.

- $\quad$ For the teeny diameter of pipes, the Inchworm robots are preferred.

- The caterpillar robots are of a clutching class.

- Due to the critical mechanisms, the walking robot generally utilized in implementation demand.

\section{Inspection Strategies:}

The inspection methodologies are significant segment of sewer robotic systems.

The CCTV camera is generally kept on the designed robotic system to capture visual upshots with identified defects 
in real-time. The SSET comprises a standard and a fish-eye CCTV frame with a combination of inclinometers to direct the device inclination. The laser profiling result in 3D profiles of sewer pipes and thermal imagery identifies thermal peculiarity. The techniques sited on acoustic, electromagnetic, and ultrasound are of non-visual class. The imagery inspection involves traditional and modern techniques.

In figure 4 , the standard operational flow for imagery techniques have been illustrated.

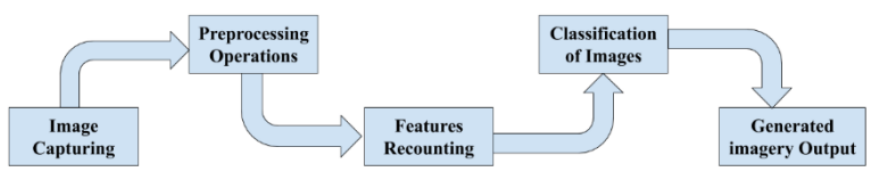

Fig. 4. Standard Operational Flow

The deep neural network techniques are now very popular due to their performance and largely came in to use from the deep neural network winning entry of Large-Scale Visual Recognition Challenge 2012. The sewer inspection task has been critically solved with images of distinct issues of sewers. The issues like infiltration, bends, cracks, deposits in pipes, tree roots, stones, holes, foreignary objects etc. The deep neural networks module for sewer issues detection task have been mentioned in the Table II.

TABLE II. Deep Neural Network modules for detection of sewer issues

\begin{tabular}{ll}
\hline \hline \multirow{2}{*}{$\begin{array}{l}\text { Deep Neural } \\
\text { Networks }\end{array}$} & Fau Only Look Once (YOLO) \\
\cline { 2 - 2 } & Single Shot Multibox Detector (SSD) \\
\cline { 2 - 2 } & Fast RCNN \\
\hline \hline
\end{tabular}

The Government of India campaigned and put forwarded the rules for cleaning and maintaining the buried infrastructures.

In Table III, the sewer Inspection and Cleaning Methods have been listed in [27].

TABLE III. The sewer Inspection and Cleaning Methods

\begin{tabular}{|c|c|c|}
\hline \multirow{3}{*}{$\begin{array}{l}\text { Sewer } \\
\text { Inspection } \\
\text { Methods }\end{array}$} & $\begin{array}{l}\text { Methods } \\
\text { Used }\end{array}$ & Involved Appearances \\
\hline & $\begin{array}{l}\text { Direct } \\
\text { Method }\end{array}$ & Explicit Visual Inspection \\
\hline & $\begin{array}{l}\text { Indirect } \\
\text { Method }\end{array}$ & $\begin{array}{ll}\text { - } & \text { Sonar Systems } \\
\text { - } & \text { Closed Circuit Camera } \\
\text { - } & \text { Light and Mirror }\end{array}$ \\
\hline $\begin{array}{l}\text { Sewer } \\
\text { Cleaning } \\
\text { Methods }\end{array}$ & $\begin{array}{l}\text { Manual } \\
\text { Methods }\end{array}$ & $\begin{array}{ll}\text { - } & \text { Scraper } \\
\text { - } & \text { Manila Rope and Cloth Ball } \\
\text { - } & \text { Sectional Sewer Rods }\end{array}$ \\
\hline
\end{tabular}

$\begin{array}{lll}\text { Mechanica } & \text { Sewer Cleaning Bucket } \\ \text { 1 Methods } & \text { Machine } \\ & \bullet \text { Rodding Machine with } \\ & \text { Flexible Sewer Rods } \\ & \text { Hydraulically Propelled } \\ & \text { Devices } \\ \bullet & \text { Velocity Cleaners (Jetting } \\ & \text { Machines) } \\ \bullet & \text { Dredger (Clam-shell) } \\ \bullet & \text { Gully Emptier }\end{array}$

The Central Public Health \& Environmental Engineering Organisation (CPHEEO) came up with the act of Prohibition of Employment as Manual Scavengers and their Rehabilitation in 2013, Swachh Bharat Mission - Urban (SBM-U).

\section{- Discernments of PMC Survey:}

There are two significant maintenance types which generally performed in every six months such as Preventive maintenance and Trouble shouting maintenance. Generally, the sewer pipes are of distinct diameters ranging from $100 \mathrm{~mm}$ to $1800 \mathrm{~mm}$ and of distinct materials such as bid-iron, PVC, RCC as well as of Net Pressure ranging from 1 to 4 . The RCC pipes are mostly used for buried sewers in the current scenario. In Pune, there is $2167 \mathrm{~km}$ of sewer line and 2187 manhole (Chambers) for intervening purpose. In the survey at Pune Municipal Corporation (PMC, Pune, India), it has been observed that Jetting Machine plays an important role for cleaning purpose of underground sewers. It is again categorized in the three types as given below.

- Simple Jetting Machine - used only for cleaning purpose

- Suction Cum Jetting Machine - used for cleaning as well as for suctioning sewer deposits

- Sewer Suction Cum Jetting Machine with a Recycler - used for cleaning and suctioning of sewer deposits as well as collected sewer water is treated (recycled) for repetitive utilization

TABLE IV. Technical Information about Jetting Machine

\begin{tabular}{ll}
\hline \hline Detailing & Caliber \\
\hline $\begin{array}{l}\text { fresh water tank } \\
\text { capacity }\end{array}$ & 3000 Ltrs or 6000 Ltrs \\
total tank capacity & 3000 Ltrs or 6000 Ltrs \\
high pressure pump & $100-150 \quad$ lpm (Litre per \\
& minute) \\
maximun pressure & $100 \mathrm{bar}$ \\
jet length & $80-100 \mathrm{~m}$ \\
\hline \hline
\end{tabular}


TABLE V. Technical Information about Sewer Suction Cum Jetting Machine With a Recycler

\begin{tabular}{lc}
\hline \hline \multicolumn{1}{c}{ Detailing } & Caliber \\
\hline Capacity of sludge tank & $9000 \mathrm{Ltrs}$ \\
fresh water tank capacity & $3000 \mathrm{Ltrs}$ \\
Total tank capacity & $3000 \mathrm{Ltrs}$ \\
high pressure pump & $400 \mathrm{lpm}(\mathrm{Litre}$ per minute) \\
maximun pressure & $200 \mathrm{bar}$ \\
jet length & $120 \mathrm{~m}$ \\
vaccum pump & $4200 \mathrm{~m} 3 / \mathrm{hr}$ \\
Maximum vaccum & $85 \%$ \\
maximun Pressure & $0.5 \mathrm{bar}$ \\
length & $15 \mathrm{~m}$ (projecting 10m) \\
\hline \hline
\end{tabular}

TABLE VI. Drawbacks OF JETTING Machine and Sewer Suction Cum Jetting Machine With a Recycler

\begin{tabular}{|c|c|}
\hline Jetting Machine & $\begin{array}{l}\text { - } \text { perform only single } \\
\text { operation } \\
\text { - } \text { costly } \\
\text { - } \text { more time consuming } \\
\text { - less efficient }\end{array}$ \\
\hline $\begin{array}{l}\text { Sewer Suction Cum } \\
\text { Jetting Machine with a } \\
\text { Recycler }\end{array}$ & $\begin{array}{l}\text { - Need of skilled operator } \\
\text { and labors } \\
\text { - high maintenance cost } \\
\text { - Need of large space for } \\
\text { operation purpose } \\
\text { - Very costly }\end{array}$ \\
\hline
\end{tabular}

The visual upshots of conducted survey at PMC (Jetting machine with real-time operations) have been shown in figure 5.
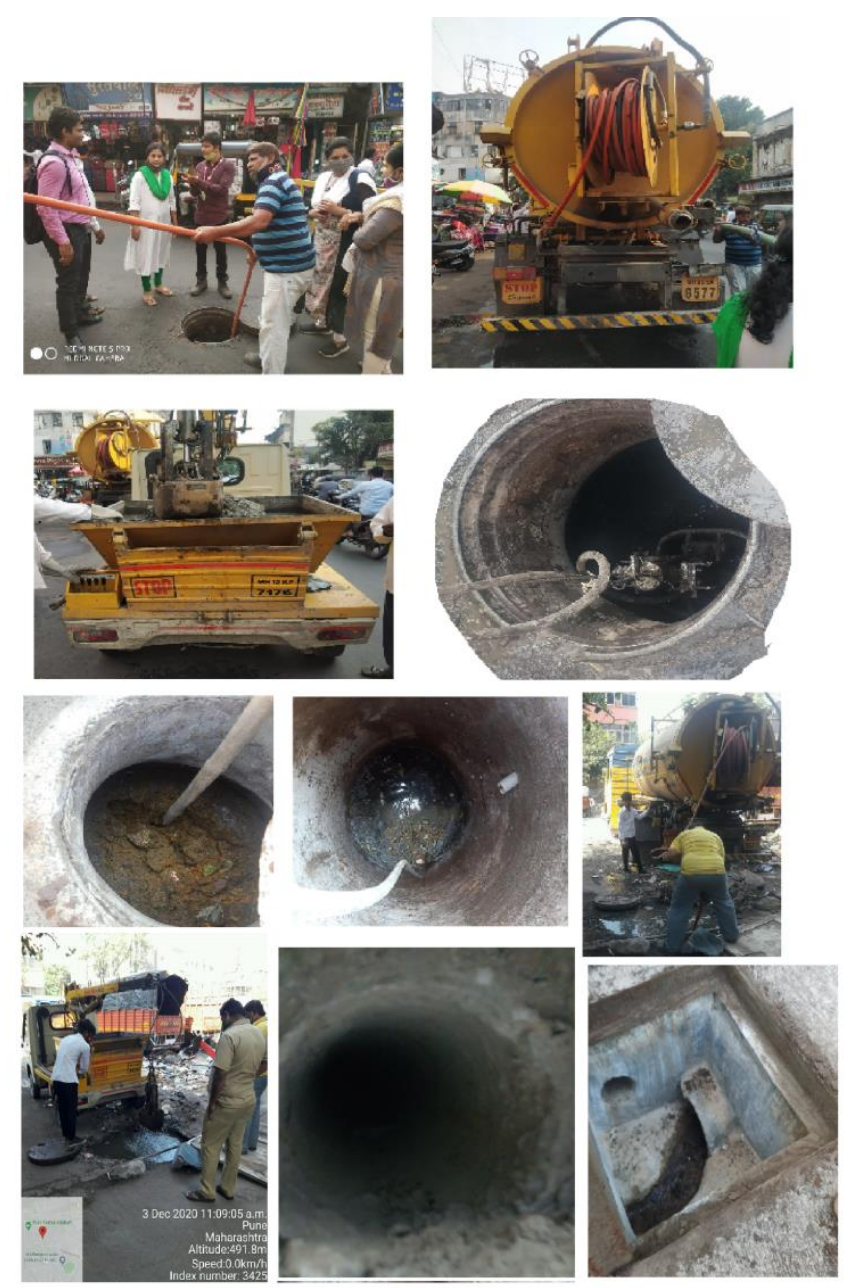

Fig. 5. Visual upshots of Jetting Machine at conducted PMC survey

As per the data received from PMC, 395 chambers had been cleaned in 39 days of length 5360 running meters by using Sewer Suction Cum Jetting Machine with a Recycler. The charges are paid by Municipal Corporation of 6400 Indian rupees per shift ( 8 hours of shift) for simple Jetting Machine, 9800 Indian rupees per shift for Suction Cum Jetting Machine and 37000 Indian rupees per shift for Sewer Suction Cum Jetting Machine with a Recycler. The large amount of water is utilized in sewer maintenance task or it can be said that water is wasted in sewers.

Due to decade-old, fuzzy, and less efficient methodical approach, this machine is not an impactful and finest option for sewer maintenance and blockage removal task.

\section{Conclusion}

The detection of real time water pollutants is a challenging task. The various methods are presented in literature but still a very few works are present for detection of BOD, COD, TSS, and Hydrogen sulfide. In future, the work can be focused on design and development of fast, cost effective, real time water pollution monitoring system with 
early warning detection using newly developed and advanced sensor nodes.

All in all, the sewer robotic systems have resolved the cardinal point of Manual Scavenging. It is cogitated that the contrived systems mostly focus on identification of sewer issues but no authentic work for detection and removal of sewer blockages with substantial algorithm and strategy in real-time where human intervention is not conceivable. Also, the developed robotic system should be cost effective with standardized accuracy matrix. The methodical approach has been clearly overviewed to extend a province of sewer robotics.

\section{Conflict of Interest}

The authors declare no conflict of interest.

\section{Author Contributions}

Saniya Ansari, S. M. Khairnar, Ravindra R. Patil, and Rupali S. Kokate conducted survey at Pune Municipal Corporation for buried infrastructure and current sewer inspection techniques. Also, they assessed and convoked crucial outcomes from literature review. Saniya Ansari and S. M. Khairnar gave valuable inputs and data for research article. The scientific writing in this research article have been completed very skillfully from analyzed data and conducted research by Saniya Ansari, S. M. Khairnar, Ravindra R. Patil and Rupali S. Kokate. At the length, all authors approved the final version of research article.

\section{Acknowledgment}

The authors would like to thank Department of Biotechnology, New Delhi, India (DBT, New Delhi India), for funding under SPRING Project in collaboration with India-EU water cooperation, Horizon 2020(Ref No.: BT/IN/EU$\mathrm{WR} / 60 / \mathrm{SP} / 2018$. We also thank the anonymous reviewers for their valuable comments that greatly improved this article.

\section{References}

[1] Dwivedi, A. K., "Researches in water pollution: A review,". International Research Journal of Natural and Applied Sciences, 4, 118-142., 2017.

[2] R. Karthik Kumar, M. Chandra Mohan, S. Vengateshapandiyan, M. Mathan Kumar, R. Eswaran, "Solar based advanced water quality monitoring system using wireless sensor network," International Journal of Science, Engineering and Technology Research, 2014.

[3] Pradeepkumar M, Monisha J., "The Real Time Monitoring of Water Quality in IoT Environment.," International Journal of Innovative Research in Science, Engineering and Technology, 2015.
[4] Kedia, Nikhil, "Water Quality Monitoring for Rural Areas- a Sensor Cloud Based Economical Project," 1st International Conference on Next Generation Computing Technologies (NGCT), 2015.

[5] Shahid Ahmed and Saba Ismail, "Water Pollution and Its Sources, Effects \& Management," A Case Study of Delhi International Journal of Current Advanced Research, vol. 7, Feb. 2018.

[6] Cengiz Koparan, Ali BulentKoc, Charles V. Privette and Calvin B. Sawyer, "In Situ Water Quality Measurements Using an Unmanned Aerial Vehicle (UAV) System,” Water, vol. 10, 2018.

[7] Peter Kruse, "Review on water quality sensors" Journal of Physics D: Applied Physics, J. Phys. D: Appl. Phys. 51, 2018.

[8] Evizal Abdul Kadir, Abdul Syukur, "Smart Sensor Node of WSNs for River Water Pollution Monitoring System," at https://www.researchgate.net/publication/33396594 6, April 2019.

[9] Cengiz Koparan, Ali Bulent Koc, “Autonomous In Situ Measurements of Noncontaminant Water Quality Indicators and Sample Collection with a UAV," Department of Agricultural Sciences, Clemson University, Clemson, SC 29634, USA; ckopara@clemson.edu (C.K.), privett@clemson.edu (C.V.P.); calvins@clemson.edu (C.B.S.), March 2019.

[10] Annasamy Gowri and ArunkumarKathiravan, "Fluorescent Chemosensor for Detection of Water Pollutants," C Springer Nature Singapore Pte Ltd. 2020.

[11] Kofi Sarpong Adu-Manu, Cristiano Tapparello, and Wendi Heinzelman, "Water Quality Monitoring Using Wireless Sensor Networks: Current Trends and Future Research Directions," ACM Transactions on Sensor Networks, vol. 13, no. 1, article 4, 2017.

[12] Charef, A., Ghauch, A., Bauss and, P., \& MartinBouyer, M., "Water quality monitoring using a smart sensing system. Measurement," vol. 28, pp. 219-224, Springer Nature, Singapore Pte Ltd., 2020 .

[13] G.A. Ibañez and G.M. Escandar, S.C. Mukhopadhyay \& A. Mason, "Real-Time Water Quality Monitoring," SSMI 4, pp. 45-64, SpringerVerlag Berlin Heidelberg, 2013.

[14] Richa Soni, Mahesh Soni and Dericks Praise Shukla, "Emerging Techniques and Materials for Water Pollutants Detection," Springer Nature Singapore Pte Ltd., 2020

[15] R. Kirkham, P.D. Kearney and K.J. Rogers, "PIRAT - A system for quantitative sewer 
assessment," In Proc. Int. Conf. Field and Service Robotics (FSR '99), CMU, Pittsburgh (PA), pp. 7 12, 1999.

[16] H.B. Kuntze, D. Schmidt, H. Haffner, and M. Loh. "KARO - A flexible robot for smart sensor-based sewer inspection," In Proc. 12th Int. No- Dig Conference, Hamburg, pp. 367-374, 1995.

[17] Kirchner and J. Hertzberg, "A prototype study of an autonomous robot platform for sewerage system maintenance," Autonomous Robots, vol. 4, pp. 319331,1997 .

[18] Rome, J. Hertzberg, F. Kirchner, U. Licht, H. Streich and Th. Christaller, "Towards autonomous sewer robots: The MAKRO project," J. Urban Water, 1:57-70, 1999.

[19] Amir A. F. Nassiraei, Yoshinori Kawamura, Alireza Ahrary, Yoshikazu Mikuriya and Kazuo Ishii, "Concept and Design of A Fully Autonomous Sewer Pipe Inspection Mobile Robot "KANTARO"," IEEE International Conference on Robotics and Automation, Roma, Ital, pp. 136-143, 2007.

[20] D. Alejo, G. Mier, C. Marques, F. Caballero, L. Merino and P. Alvito, "SIAR: A Ground Robot Solution for Semi-autonomous Inspection of Visitable Sewers," Springer Tracts in Advanced Robotics, vol, 132, 2020.

[21] Vaani, Simerna J. Sushil, Vani Kunjamma U.S, Akshaya Ramachandran, Dr. Thulasi Bai V. and B. Thyla, "BhrtyArtana-A pipe cleaning and inspection robot," IEEE 3rd International Conference on Sensing, Signal Processing and Security (ICSSS), pp. 422-425, 2017.

[22] Joakim Bruslund Haurum and Thomas B. Moeslund, "A Survey on Image-Based Automation of CCTV and SSET Sewer Inspections," Automation in Construction - An International Research Journal (Elsevier), 2020.

[23] Josep M. Mirats Tur and William Garthwaite, "Robotic devices for water main in-pipe inspection: A survey," Journal of Field Robotics (Wiley), vol. 27, pp. 491-508, 2010.

[24] Sharun Mendonca, Khalid Mohammad Zulqurnain*, K. M. Abdul Razack, Mohammed Zohair, Rolwin Wilston Carlo, "Multi Functional Android Controlled Robotic Arm for Drilling, Cutting and Cleaning Application," Journal of Mechanical Engineering and Automation, vol. 7, pp. 89-93, 2017.

[25] José Saenz, Norbert Elkmann, Thomas Stuerze, Sven Kutzner, and Heiko Althoff, "Robotic systems for cleaning and inspection of large concrete pipes," IEEE 1st International Conference on Applied
Robotics for the Power Industry Delta Centre-Ville Montréal, Canada, 2010.

[26] Roussialian M., Al Zanbarakji H., Khawand A., Rahal A., Owayjan M., "Design and Development of a Pipeline Inspection Robot,” In: Rizk R., Awad M. (eds) Mechanism, Machine, Robotics and Mechatronics Sciences, Mechanisms and Machine Science, vol 58, 2019.

[27] Manual on Storm Water Drainage Systems Central Public Health \& Environmental Engineering Organisation (CPHEEO), Ministry of Housing and Urban Affairs, Government of India, 2019. [Online]. Available: - http://cpheeo.gov.in/.

[28] Omkar S. Vaidya, Ravindra Patil, Gayatri, M. Phade, S. T. Gandhe, "Embedded Vision Based Cost Effective Tele-Operating Smart Robot," International Journal of Innovative Technology and Exploring Engineering, vol. 8(7), pp.1544-1550, 2019.

[29] Ravindra R. Patil, Omkar S. Vaidya, Gayatri, M. Phade, S. T. Gandhe. "Qualified Scrutiny for RealTime Object Tracking Framework," International Journal on Emerging Technologies, vol. 11(3), pp.313-319, 2020.

\section{AUTHORS PROFILE}

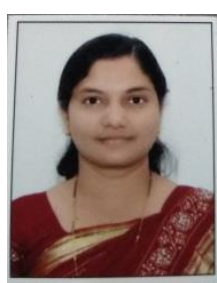

Dr. Saniya Ansari is working as an Associate Professor, in Electronics and Telecommunication department, in Dr D Y Patil School of Engineering, Pune. She holds $\mathrm{BE}$ in $\mathrm{E} \& \mathrm{TC}$ engineering, ME in Electronics Engineering and Ph.D. in ECE. Her areas of expertise are Robotics and automation, Image processing, Wireless sensor Networks etc. She has 17 years teaching experience and handled the various administrative responsibilities like Head of the Department, PG Coordinator. She has a recipient of Horizon 2020 SPRING Project, of water Cooperation. She is actively engaged in aquatic robot designing for water pollutants monitoring. She has published various papers in National/International Journal.

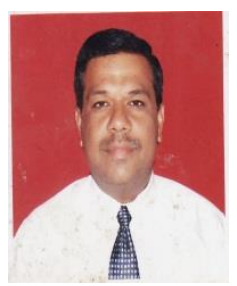

Dr. S. M. Khairnar is Gold Medalist at PG \& Ph.D. in Engineering Mathematics. He has 30 years of teaching and 21 years of research experience. His major research areas of interests are Geometric Functions Theory and Image Processing. He has published 127 research papers in peer reviewed National \& International journals and Conferences. He is a recognized Ph.D. guide by three renowned universities in India including University of Pune. Sixteen students have completed their Ph.D. under his guidance \& presently supervising six students for Ph.D. He has delivered total 110 invited talks on various topics for 
promoting interdisciplinary research. He has visited eleven foreign Universities and delivered plenary and invited talks at various International Conferences held at Canada, London, Oxford, Pakistan, Malaysia, Nepal, Singapore, Thailand, UK, Germany, UAE \& Egypt etc. He has organized many conferences, workshops, seminars \& symposiums for faculty and students. He has successfully completed five research projects funded by University of Pune, Department of Science \& Technology, Government of India, NBHM \& Department of Atomic Energy, DBT Government of India. He is reviewer of several National \& International Journals. He has worked on several bodies of the universities like, the Board of Studies, Research Recognition Committee, Staff Selection Committee and several others. Presently he is working as Professor and Head, Department of Engineering Sciences and Dean (R\&D) at D. Y. Patil School of Engineering, Pune, Maharashtra, India.

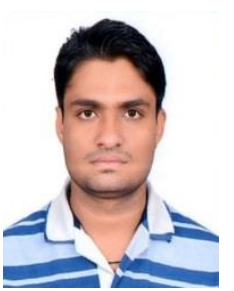

Ravindra R. Patil is Junior Research Fellow (JRF) in SPRING Research Project SPRING Project at DYPSOE, Pune, India. He is also Ph.D. research student at UiT - The Arctic University of Tromso Norway, Norway. He completed the graduation B.E. (E\&TC) in 2017 and Master of Engineering (M.E.) in (E\&TC) in 2020. He has published two research papers in Peer reviewed International Scopus indexed journals. His research interests are Computer Vision, Machine Learning, Deep Learning and Robotics.

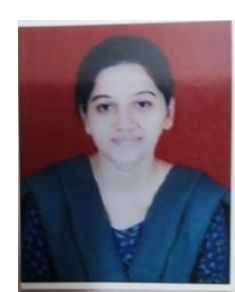

Rupali Shrikant Kokate is Junior Research Fellow (JRF) in SPRING Research Project SPRING Project at DYPSOE, Pune, India. She received B.E. in Electronics \& Telecommunications in 2012 and M.E. in Electronics \& Telecommunications in 2016. She has published 4 research papers in International journals. Her area of expertise consists of embedded system and Robotics. 